\title{
Accuracy Between CURB-65 Score and PSI in Determining The Prognosis of Community-Acquired Pneumonia Patients at H. Adam Malik General Hospital, Medan
}

\author{
Fransisco Sentosa Pakpahan ${ }^{1}$, Syamsul Bihar ${ }^{1}$, Fajrinur Syarani ${ }^{1}$, \\ Putri Chairani Eyanoer² \\ ${ }^{1}$ Department of Pulmonology and Respiratory Medicine, Faculty of Medicine, \\ Universitas Sumatera Utara, Medan \\ ${ }^{2}$ Department of Community and Preventive Medicine, Faculty of Medicine, \\ Universitas Sumatera Utara, Medan
}

\section{Corresponding Author:}

Fransisco Sentosa Pakpahan | Department of Pulmonology and Respiratory Medicine, Faculty of Medicine, Universitas Sumatera Utara, Medan |

franzetocoolpakpahan@gmail.com

Submitted: February $19^{\text {th }}, 2021$

Accepted: March $1^{\text {st }}, 2021$

Published: June $23^{\text {th }}, 2021$

Respir Sci. 2021; 1(3): 174-181

https://doi.org/10.36497/respirsci.v1i3.25

\begin{abstract}
Background: Community-Acquired Pneumonia (CAP) is an important problem associated with morbidity and mortality. An accurate initial assessment is required before starting management of a CAP patient to determine the prognosis of the patient as early as possible. The CURB-65 score and PSI (Pneumonia Severity Index) are initial assessment scores that can be used. This study aimed to compare the accuracy between the CURB-65 score and the PSI in determining the prognosis in CAP patients at $\mathrm{H}$. Adam Malik General Hospital Medan.
\end{abstract}

Method: A descriptive study was conducted on 76 patients diagnosed with CAP. Each patient was assessed for their CURB-65 score, PSI class and mortality within 30 days of admission. Data were collected through patient medical records diagnosed CAP in 2018 and performed statistical analysis using $2 \times 2$ tables.

Results: The CURB-65 $\geq 3$ score showed accuracy (71.0\%), sensitivity (53.8\%), and specificity ( $89,2 \%)$. The CURB- $65 \geq 2$ score showed accuracy $(75.0 \%)$, sensitivity $(82.1 \%)$, and specificity (67.6\%). Meanwhile, the Class IV-V PSI showed accuracy $(77.6 \%)$, sensitivity (87.2\%) and specificity (67.6\%).

Conclusion: The accuracy of the PSI is higher when compared to the CURB-65 score in determining the prognosis of CAP patients at H. Adam Malik General Hospital Medan. Although PSI is more accurate, CURB-65 is simpler, easier and less expensive to use.

Keywords: CURB-65, PSI, accuracy, prognosis, communityacquired pneumonia

\section{INTRODUCTION}

\section{Community-Acquired Pneumonia} (CAP) is an important problem associated with morbidity and mortality. ${ }^{1}$ CAP is an acute, community-acquired inflammation of the lung parenchyma. ${ }^{2}$ CAP occurs in 35 cases per 1000 people each year, especially in the elderly with a 10-fold increase in incidence. ${ }^{1}$ In the United States, pneumonia is the leading cause of death 
associated with infections with potentially serious complications such as respiratory failure and sepsis. ${ }^{3}$ Every year in the United States (US) an average of 5 to 6 million people suffer from CAP, and more than 1 million of them require hospitalization. About $10-20 \%$ of patients suffering from CAP need to be admitted to the Intensive Care Unit (ICU), and about $20-50 \%$ of them eventually die. ${ }^{4}$ In Japan, Community Pneumonia is the 4th cause of death. In Indonesia, pneumonia is included in the top 10 inpatient diseases at the hospital. ${ }^{2}$

Table 1. Components of Pneumonia Severity Index $(\mathrm{PSI})^{2}$

\begin{tabular}{|c|c|}
\hline Characteristics & Score \\
\hline Demographic factors & $\begin{array}{c}\text { Age } \\
\text { (years) }\end{array}$ \\
\hline Demographic factors & $\begin{array}{c}\text { Age } \\
\text { (years) }\end{array}$ \\
\hline Men & -10 \\
\hline Women & +10 \\
\hline \multicolumn{2}{|l|}{ Nursing home resident } \\
\hline \multicolumn{2}{|l|}{ Coexisting illnesses } \\
\hline Neoplastic disease & +30 \\
\hline Liver disease & +20 \\
\hline Congestive heart failure & +10 \\
\hline Cerebrovascular disease & +10 \\
\hline Renal disease & +10 \\
\hline \multicolumn{2}{|l|}{ Findings on physical examination } \\
\hline Altered mental status & +20 \\
\hline Respiratory rate $\geqslant 30 / \mathrm{min}$ & +20 \\
\hline Systolic blood pressure $<90 \mathrm{~mm} \mathrm{Hg}$ & +20 \\
\hline Temperature $<35^{\circ} \mathrm{C}$ or $\geqslant 40^{\circ} \mathrm{C}$ & +15 \\
\hline Pulse $\geqslant 125$ beats/min & +10 \\
\hline \multicolumn{2}{|l|}{ Laboratory and radiographic findings } \\
\hline $\mathrm{pH}<7,35$ & +30 \\
\hline $\begin{array}{l}\mathrm{BUN}>10.7 \mathrm{mmol} / \mathrm{L} \text { or } \mathrm{BUN}>29 \\
\mathrm{mg} / \mathrm{dL}\end{array}$ & +20 \\
\hline Sodium $<130 \mathrm{mEq} / \mathrm{L}$ & +20 \\
\hline 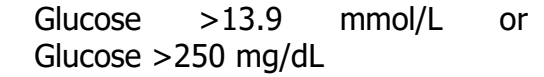 & +10 \\
\hline Haematocrit <30\% & +10 \\
\hline $\begin{array}{l}\text { The partial pressure of arterial } \\
\text { oxygen }<60 \mathrm{~mm} \mathrm{Hg}\end{array}$ & +10 \\
\hline Pleural effusion & +10 \\
\hline
\end{tabular}

Each variable has its score and is calculated into 5 classes as in (Table 2). ${ }^{2}$ Although PSI has a high discriminatory value, the calculation is complex, difficult to use in a hospital with inadequate facilities and infrastructure and ignores disease severity in young patients without comorbidities. $^{5}$

Table 2. Total score of PSI in Severity Risk Class ${ }^{2}$

\begin{tabular}{cc}
\hline Severity Risk Class & Total Score of PSI \\
\hline I & $\leq 50$ \\
II & $51-70$ \\
III & $71-90$ \\
IV & $91-130$ \\
V & $>130$ \\
\hline
\end{tabular}

Whereas CURB-65 is a simpler clinical score than PSI because it only uses five variables (Table 3).

Table 3. Components of CURB-65 Score ${ }^{2}$

\begin{tabular}{lc}
\hline \multicolumn{1}{c}{ Characteristics } & Score \\
\hline Confusion & 1 \\
Urea $>7 \mathrm{mmol} / \mathrm{L}$ or Blood Urea Nitrogen & 1 \\
(BUN) $>19 \mathrm{mg} / \mathrm{dL}$ & \\
Respiratory Rate $\geq 30 /$ minute & 1 \\
Blood pressure $($ Systolic $<90 \mathrm{mmHg}$ or & 1 \\
Diastolic $\leq 60 \mathrm{mmHg})$ & \\
Age $\geq 65$ years old & 1 \\
\hline
\end{tabular}

Confusion (defined as disorientation in people, time and place), urea (urea $>7$ $\mathrm{mmol} / \mathrm{L}$ or BUN (Blood Urea Nitrogen) $>19$ $\mathrm{mg} / \mathrm{dL}$ ), respiratory rate (respiratory rate $\geq 30$ /minute), blood pressure (systolic $<90$ $\mathrm{mmHg}$ or diastolic $\leq 60 \mathrm{mmHg}$ ) and age (older than 65 years). ${ }^{6}$

Each scoring system has strengths and weaknesses. The PSI is well validated for identifying low-risk patients but may underestimate illness severity in young, otherwise healthy patients, due to the heavy weighting it accords to age and comorbidities. On the other hand, CURB65 may better identify patients at the severe end of the spectrum, because it evolved from prediction rules originally designed to identify patients with severe CAP. 
In the study of Michelle et al, it was said that the PSI score of class IV/V was better than CURB-65 $\geq 3$ score in predicting patient mortality within 30 days. ${ }^{7}$ Meanwhile, in a study conducted by Kim et al at 14 hospitals in Korea it was said that the 30-day mortality rate for CAP patients based on the CURB-65 score was more valid for lower scores, while the PSI score was more valid for higher scores. ${ }^{8}$ This is in line with research conducted by Alavi-Moghaddam which concluded that the CURB-65 score is a more recommended method than the PSI score for predicting mortality in CAP patients. ${ }^{9}$ So, this study aimed to compare the accuracy between the CURB-65 score and the PSI score in determining the prognosis in CAP patients.

\section{METHOD}

A cohort retrospective study was conducted on patients diagnosed with CAP. Data were collected from medical records of patients diagnosed with CAP from January-December 2018. Medical records were reviewed to confirm the diagnosis of CAP. The diagnosis of CAP in this study is based on the Indonesian Society of Respirology (ISR), a definite diagnosis of CAP is confirmed if there is an infiltrate/air bronchogram on the chest X-ray with any of the following symptoms or signs: cough, change in sputum/purulent characteristics, body temperature $\geq 38^{\circ} \mathrm{C}$ (axillary)/history of fever, chest pain, shortness of breath, on physical examination, there may be signs of consolidation, bronchial breath sounds and crackles, leukocytes $\geq 10,000$ or $\leq 4500$.

The sample in this study must meet the inclusion criteria and exclusion criteria. The inclusion criteria in this study were as follows: age more than 18 years, admission to the H. Adam Malik General Hospital from the emergency room and the patient was diagnosed with CAP by a Pulmonologist. The exclusion criteria in this study were as follows: patients with tuberculosis, patients with aspiration pneumonia, patients who have been hospitalized previously with a length of stay more than 48 hours before admission to $H$. Adam Malik General Hospital. Prognosis in CAP patients is measured using the short-term mortality rate. This short-term mortality rate is defined as death that occurs within 30 days of hospitalization.

A total of 76 patients met the inclusion and exclusion criteria in this study. Each patient was assessed for their CURB-65 score, PSI class and mortality within 30 days of admission. This study was performed statistical analysis using $2 \times 2$ tables for each PSI class and CURB-65 score. Sensitivity, specificity, positive predictive value (PPV), negative predictive value (NPV) and accuracy are measured and compared for each cut of point PSI Class and CURB-65 score. Sensitivity is expressed as the proportion of correctly classified as true positives mortality among 
each cut of point CURB-65 score and PSI Class $(\mathrm{TP} / \mathrm{TP}+\mathrm{FN}) . \quad(\mathrm{TP}=$ True Positive Value; FN=False Negative Values) Whereas specificity is expressed as the proportion of correctly classified as true negatives among the total non-mortality patients (TN/TN+FP). (TN=True Negative Value; $\mathrm{FP}=$ False Positive Values) The positive predictive value of test (PPV) is the probability of a study subject who has mortality when restricted to those subjects who had a positive test. It can be calculated as (TP/TP+FP). The negative predictive value of a test is the probability of a study subject who will not have mortality when restricted to those subjects who test negative. It can calculate as (TN/FN+TN). The accuracy of a test is expressed as the proportion of those individuals correctly categorized by the test (those with the disease who had a positive test plus those without the disease who had a negative test result). It can be calculated as (TP+TN/TP+FP+FN+TN).

This study has been approved by the Ethical Research Committee of the Faculty of Medicine, Universitas Sumatera Utara.

\section{RESULT}

A total of 76 patients were assessed in this study. The patients in this study met inclusion and exclusion criteria. The data showed that 42 patients (55.3\%) are male and 34 patients (44.7\%) are female. The age distribution of patients in this study was evenly distributed in all age groups.
The distribution of age in this study could be seen in (Table 4). The majority The most common comorbidities in this study were hematological disorders such as anemia, thrombocytopenia, pancytopenia and bicytopenia. For comorbid diseases in this study can be seen in (Table 4).

Table 4. Demographic characteristics based on

\begin{tabular}{lcc}
\multicolumn{3}{c}{ gender, comorbidity, age and education } \\
\hline \multicolumn{1}{c}{ Characteristics } & n & \% \\
\hline Gender & & \\
Male & 42 & 55.3 \\
Female & 34 & 44.7 \\
Age & & \\
<40 years old & 14 & 18.4 \\
40 - 49 years old & 13 & 17.1 \\
50 - 59 years old & 16 & 21.1 \\
60 - 69 years old & 18 & 23.7 \\
Z70 years old & 15 & 19.7 \\
Comorbidity & & \\
Respiration & 9 & 11.8 \\
Endocrine & 17 & 22.4 \\
Cardiology & 25 & 32.9 \\
Malignancy & 11 & 14.5 \\
Electrolyte Imbalance & 30 & 39.5 \\
Gastrointestinal Tract & 15 & 19.7 \\
Neurology & 17 & 22.4 \\
Nephrology & 15 & 19.7 \\
Hematology & 31 & 40.8 \\
Hipoalbumin & 17 & 22.4 \\
HIV & 2 & 2.6 \\
Urology & 6 & 7.9 \\
No Comorbidity & 1 & 1.3 \\
Education & & \\
Primary School/No Education & 18 & 23.7 \\
Junior High School & 19 & 25 \\
Senior High School & 30 & 39.5 \\
College & 9 & 11.8 \\
\hline
\end{tabular}

The distribution of mortality within 30 days for each class of PSI and CURB-65 score can be seen in (Table 5). We can see that the higher the PSI class and the higher the CURB-65 score, the higher the mortality rate. There is a correlation between class of PSI and CURB-65 score with mortality within 30 days. The results of sensitivity, specificity, PPV, NPV and accuracy between the PSI class and the CURB-65 score are shown in (Table 6). 
Table 5. Correlation between severity score and 30-d mortality

\begin{tabular}{|c|c|c|c|c|}
\hline \multirow{3}{*}{ Severity Score } & \multirow{3}{*}{$\begin{array}{c}\text { All Patient } \\
\text { n (\%) }\end{array}$} & \multicolumn{2}{|c|}{ 30-d mortality } & \multirow{3}{*}{$\mathbf{P}$} \\
\hline & & Yes & No & \\
\hline & & n (\%) & n (\%) & \\
\hline \multicolumn{5}{|l|}{ PSI } \\
\hline Class V & $24(31.6)$ & $19(48.7)$ & $5(13.5)$ & \multirow{5}{*}{$<0.001$} \\
\hline Class IV & $22(28.9)$ & $15(38.5)$ & $7(18.9)$ & \\
\hline Class III & $18(23.7)$ & $3(7.7)$ & $15(40.5)$ & \\
\hline Class II & $7(9.2)$ & $1(2.6)$ & $6(16.2)$ & \\
\hline Class I & $5(6.6)$ & $1(2.6)$ & $4(10.8)$ & \\
\hline \multicolumn{5}{|l|}{ CURB-65 } \\
\hline 5 points & $1(1.3)$ & $1(2.6)$ & $0(0.0)$ & \multirow{7}{*}{$<0.001$} \\
\hline 4 points & $8(10.5)$ & $8(20.5)$ & $0(0.0)$ & \\
\hline 3 points & $16(21.1)$ & $12(30.8)$ & $4(10.8)$ & \\
\hline 2 points & $19(25)$ & $11(28.2)$ & $8(21.6)$ & \\
\hline 1 points & $17(22.4)$ & $6(15.4)$ & $11(29.7)$ & \\
\hline 0 points & $15(19.7)$ & $1(2.6)$ & $14(37.8)$ & \\
\hline Total & $76(100.0)$ & $39(100.0)$ & $37(100.0)$ & \\
\hline
\end{tabular}

Table 6. Accuracy for predicting mortality

\begin{tabular}{lccccc}
\hline \multicolumn{1}{c}{ Severity Score } & \%Sensitifity & \%Spesificity & \%PPV & \%NPV & \%Accuracy \\
\hline PSI & & & & & \\
Class V & 48.7 & 86.5 & 79.1 & 61.5 & 67.1 \\
Class IV-V & 87.2 & 67.6 & 73.9 & 83.3 & 77.6 \\
Class III-V & 94.9 & 27 & 57.8 & 83.3 & 61.8 \\
Class II-V & 97.4 & 10.8 & 53.5 & 80 & 55.2 \\
CURB-65 & & & & & 50 \\
=5 points & 2.6 & 100 & 100 & 49.3 & 60.5 \\
$\geq 4$ points & 23.1 & 100 & 100 & 55.2 & 71 \\
$\geq 3$ points & 53.8 & 89.2 & 16 & 64.7 & 75 \\
$\geq 2$ points & 82.1 & 67.6 & 72.7 & 43.1 & 68.4 \\
\hline 1 points & 2.6 & 37.8 & 74.5 & 93.3 & \\
\hline
\end{tabular}

The highest accuracy in this study is in the PSI IV-V class with accuracy $(77.6 \%)$, sensitivity $(87.1 \%)$ and specificity (67.6\%). The results for the CURB-65 $\geq 2$ score showed accuracy (75.0\%), sensitivity $(82.1 \%)$, and specificity $(67.6 \%)$. The results for the CURB-65 $\geq 3$ score showed accuracy $(71.0 \%)$, sensitivity $(53.8 \%)$, and specificity $(89,2 \%)$. That means that the PSI Class IV-V is more accurate in predicting mortality within 30 days of hospitalization.

\section{DISCUSSION}

The mortality of CAP in this study was $51.3 \%$ with a total sample of 76 patients (Table 1). This is not much different from the study conducted by Mortensen et al, where it was found that CAP mortality rate was $53 \%$ of the total study sample of 208 patients. ${ }^{10}$ Whereas, in a study conducted by Zhang et al, with a larger sample of 3224 patients, the mortality rate associated with CAP was $15.7 \% .{ }^{11}$ The mortality rate obtained by Zhang et al is far different from that in this study because a larger sample size will represent the state of the population.

Lanks et al attempted to carry out an epidemiological study that identified risk factors for an increased incidence of CAP and found that the magnitude of the risk of CAP increased with increasing patient age and the presence of comorbidities. These comorbidities include chronic airway 
diseases, such as chronic obstructive pulmonary disease and bronchiectasis, as well as non-respiratory problems such as cardiovascular and kidney disease. ${ }^{12}$

This relatively not much different from previous studies where almost all patients who were the subject of this study had comorbidities (Table 1 ). Only 1 patient had no comorbid disease. The most common comorbids found in this study were hematological disorders, 31 patients or $40.8 \%$ of the subjects. These hematological disorders can include anemia, thrombocytopenia, leukemia, and thrombosis. Another comorbid that is relatively common in this study is electrolyte disturbances which were found in 30 patients or as much as $39.5 \%$. These electrolyte imbalances can include hyponatremia or hypokalaemia.

Every time the PSI class increases, and the CURB-65 score increases, the mortality rate will increase (Table 2 ). This is consistent with research conducted by Wiersinga et al, which showed that the mortality rate within 30 days increases when the CURB-65 score increases. ${ }^{13}$ This is also consistent with research conducted by Kim et al, which showed that the mortality rate in 30 days increased when the PSI class increased. ${ }^{8}$ So there is a correlation between the increase in the CURB-65 score and the PSI class with mortality within 30 days of hospitalization.

Sensitivity, specificity, PPV, NPV and accuracy between the PSI class and the CURB-65 score are shown in Table 3. The focus in this study is measuring accuracy, accuracy of a test is expressed as the proportion of those individuals correctly categorized by the test (those with each cut of point score who had a positive test (mortality within 30 days hospitalization) plus those undercut of point score who had a negative test result (no mortality within 30 days hospitalization). The accuracy PSI IV-V class in this study is $77.6 \%$. The accuracy of the CURB-65 $\geq 3$ score in this study was $71 \%$, while the accuracy of the CURB-65 $\geq 2$ score in this study was $75 \%$. Therefore, in this study, it can be concluded that the highest accuracy is in PSI class IV-V. Another study that is in line with this study is a study conducted by Michelle et al It was said that the sensitivity of the PSI grade IV/V score was better than the CURB-65 score $\geq 3$ in predicting patient mortality within 30 days ( $94 \%$ vs $62 \%$ ). ${ }^{7}$

Another meta-analysis study conducted by Chalmers et al in 2010 attempted to analyze 33 cohort studies with 81,700 patients. This study compared the sensitivity and specificity levels of the PSI score. The study shows that the PSI score has a better level of accuracy compared to the CURB-65 score and the CURB-65 score, as evidenced by the larger PSI area under the curve (AUC) (82\% vs 79\%). ${ }^{14}$ This PSI score has higher accuracy than the CURB-65 score because the PSI score uses 20 variables, but this score takes longer to collect data from these 20 variables when compared to the CURB-65 score which only uses 5 variables.

The limitation of this study is that this study is retrospective, there can be bias in the information obtained. Comorbid obtained from the final diagnosis of 
patients who died or survived in this study patient may not represent all the comorbid present in these patients because some examinations have never been done before. Patients who survive in this study are patients who discarded for outpatient treatment, and there is no follow-up after the patient discarded, the patient discarded for outpatient treatment may go back to the hospital after discarded.

\section{CONCLUSION}

A severity score can be used to predict mortality within 30 days of a patient with CAP. The Result of Class IV-V PSI showed accuracy (77.6\%), sensitivity $(87.1 \%)$ and specificity (67.6\%). The results for the CURB-65 $\geq 2$ score showed accuracy $(75.0 \%)$, sensitivity $(82.1 \%)$, and specificity $(67.6 \%)$. The results for the CURB-65 $\geq 3$ score showed accuracy $(71.0 \%)$, sensitivity $(53.8 \%)$, and specificity $(89,2 \%)$. The accuracy of class IV-V PSI is higher when compared to the CURB-65 $\geq 3$ and CURB-65 $\geq 2$ score in determining the prognosis of CAP patients at H. Adam Malik General Hospital Medan. Although PSI is more accurate, CURB-65 is simpler, easier and less expensive to use.

\section{REFERENCES}

1. Restrepo MI, Faverio $P$, Anzueto A. Long-term prognosis in communityacquired pneumonia. Curr Opin Infect Dis. 2013;26(2):151-158.

2. Perhimpunan Dokter Paru Indonesia. Pneumonia Komunitas. 2nd ed. Jakarta: Badan Penerbit FK UI; 2014.
3. Wuerth BA, Bonnewell JP, Wiemken $\mathrm{TL}$, Arnold FW. Trends in pneumonia mortality rates and hospitalizations by organism, United States, 20022011. Emerg Infect Dis. 2016;22(9):1624-1627.

4. Benisi R, Bayat-Makoo Z, Mobaiyen $\mathrm{H}$. Prognostic factors and outcome of patients hospitalized with community acquired Pneumonia. J Anal Res Clin Med. 2018;6(2):86-92.

5. Ahn JH, Choi EY. Expanded A-DROP Score: A New Scoring System for the Prediction of Mortality in Hospitalized Patients with Community-acquired Pneumonia. Sci Rep. 2018;8(1).

6. Sintes $H$, Sibila $O$, Waterer GW, Chalmers JD. Severity assessment tools in CAP. Eur Respir Monogr. 2014;63:88-104.

7. Ananda-Rajah MR, Charles PGP, Melvani S, Burrell LL, Johnson PDR, Grayson ML. Comparing the pneumonia severity index with CURB65 in patients admitted with community acquired pneumonia. Scand J Infect Dis. 2008;40(4):293300.

doi: $10.1080 / 00365540701663381$

8. Kim HI, Kim SW, Chang $\mathrm{HH}_{\text {, et al. }}$ Mortality of community-acquired pneumonia in Korea: Assessed with the pneumonia severity index and the CURB-65 score. J Korean Med Sci. 2013;28(9):1276-1282.

9. Alavi-Moghaddam M, Bakhshi $\mathrm{H}$, Rezaei B, Khashayar P. Pneumonia severity index compared to CURB-65 in predicting the outcome of 
community acquired pneumonia among patients referred to an Iranian emergency department: A prospective survey. Brazilian J Infect Dis. 2013;17(2):179-183.

10. Mortensen EM, Coley CM, Singer DE, et al. Causes of death for patients with community-acquired pneumonia: Results from the pneumonia patient outcomes research team cohort study. Arch Intern Med. 2002;162(9):1059-1064.

11. Zhang ZX, Zhang W, Liu $P$, et al. Prognostic value of Pneumonia Severity Index, CURB-65, CRB-65, and procalcitonin in communityacquired pneumonia in Singapore. Proc Singapore Healthc. 2016;25(3):139-147.

12. Lanks CW, Musani AI, Hsia DW. Community-acquired Pneumonia and Hospital-acquired Pneumonia. Med Clin North Am. 2019;103(3):487-501.

13. Wiersinga $\mathrm{WJ}$, Bonten $\mathrm{MJ}$, Boersma WG, et al. Management of community-acquired pneumonia in adults: 2016 guideline update from the Dutch Working Party on Antibiotic Policy (SWAB) and Dutch Association of Chest Physicians (NVALT) - the University of Groningen research portal. Neth J Med. 2018;76(1):4-13.

14. Chalmers JD, Singanayagam A, Akram AR, et al. Severity assessment tools for predicting mortality in hospitalised patients with community-acquired pneumonia. Systematic review and meta-analysis. Thorax. 2010;65(10):878-883. 